\title{
Optimal Duration of Low Molecular Weight Heparin for the Treatment of Cancer-Related Deep Vein Thrombosis: The Cancer-DACUS Study
}

Mariasanta Napolitano, Giorgia Saccullo, Alessandra Malato, Delia Sprini, Walter Ageno, Davide Imberti, Doris Mascheroni, Eugenio Bucherini, Pina Gallucci, Andrea D’Alessio, Tullia Prantera, Pietro Spadaro, Stefano Rotondo, Pierpaolo Di Micco, Vincenzo Oriana, Oreste Urbano, Francesco Recchia, Angelo Ghirarduzzi, Lucio Lo Coco, Salvatrice Mancuso, Alessandra Casuccio, Giovam Battista Rini, and Sergio Siragusa

See accompanying editorial doi: 10.1200/JCO.2014.55.6977 and article doi: 10.1200/JCO.2014.56.5184

Author affiliations appear at the end of this article.

Published online ahead of print at www.jco.org on Month XX, 2014.

Authors' disclosures of potential conflicts of interest and author contributions are found at the end of this article.

Clinical trial information: NCT00450645 Corresponding author: Sergio Siragusa, MD, Dipartimento Biomedico di Medicina Interna e Specialisticiche (DiBiMIS), Università degli Studi di Palermo, Via del Vespro 127, 90127 Palermo, Italy; e-mail: sergio.siragusa@ unipa.it.

() 2014 by American Society of Clinical Oncology

0732-183X/14/3299-1/\$20.00

AQ: E DOI: 10.1200/JCO.2013.51.7433

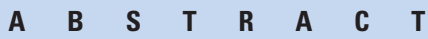

\section{Purpose}

We evaluated the role of residual vein thrombosis (RVT) to assess the optimal duration of anticoagulants in patients with cancer who have deep vein thrombosis (DVT) of the lower limbs.

\section{Patients and Methods}

Patients with active cancer and a first episode of DVT treated with low molecular weight heparin (LMWH) for 6 months were eligible. Patients were managed according to RVT findings: those with RVT were randomly assigned to continue LMWH for an additional 6 months (group A1) or to discontinue it (group A2), and patients without RVT stopped LMWH (group B). The primary end point was recurrent venous thromboembolism (VTE), and the secondary end point was major bleeding. Patients were observed for 1 year after LMWH discontinuation.

\section{Results}

Between October 2005 and April 2010, 347 patients were enrolled. RVT was detected in 242 patients (69.7\%); recurrence occurred in 18 of the 119 patients in group A1compared with 27 of 123 patients in group A2. The adjusted hazard ratio (HR) for group A2 versus A1 was 1.58 (95\% $\mathrm{Cl}, 0.8$ to $3.0 ; P=.175)$. Three of the 105 patients in group $\mathrm{B}$ developed recurrent VTE; adjusted $\mathrm{HR}$ for group $\mathrm{A} 1$ versus $\mathrm{B}$ was $6.0(95 \% \mathrm{Cl}, 1.7$ to $21.2 ; P=.005)$. Three major bleeding events occurred in group $A 1$, and two events each occurred in groups $A 2$ and $B(P=.880)$. Overall, 42 patients $(12.1 \%)$ died during follow-up as a result of cancer progression.

\section{Conclusion}

In patients with cancer with a first DVT, treated for 6 months with LMWH, absence of RVT identifies a population at low risk for recurrent thrombotic events. Continuation of LMWH in patients with RVT up to 1 year did not reduce recurrent VTE.

\section{J Clin Oncol 32. (C) 2014 by American Society of Clinical Oncology}

\section{INTRODUCTION}

Venous thromboembolism (VTE) is a frequent complication in patients with cancer. ${ }^{1-3}$ Management of deep vein thrombosis (DVT) and/or pulmonary embolism (PE) may be difficult in this population because of the high risk of both recurrent events and major hemorrhages, even if adequate vitamin $\mathrm{K}$ antagonist (VKA) therapy is administered. ${ }^{4}$ It has been reported that the use of low molecular weight heparin (LMWH) is more effective than VKA, ${ }^{5}$ and $\mathrm{LMWH}$ is now recommended as the first option for patients with any type of cancer who have acute VTE. ${ }^{6,7}$ There is less evidence regarding the duration of anticoagulant treatment; current guidelines suggest that patients with cancerrelated DVT should be treated for 6 months or even longer ${ }^{6}$ if the cancer is still active, but such recommendations are not based on randomized trials, and thus there is some uncertainty. In noncancer patients, the risk of recurrence is usually greatest during the first year after treatment withdrawal and gradually diminishes, ${ }^{8}$ although the increased bleeding risk may offset the benefits of prolonged therapy. ${ }^{9}$ For this reason, new immediately available and easily determinable markers, such as residual vein thrombosis (RVT) and the D-dimer test, have been proposed to individualize treatment for secondary prevention of VTE. ${ }^{10-13}$ Results from prospective studies have shown that the absence of RVT or a 
Napolitano et al

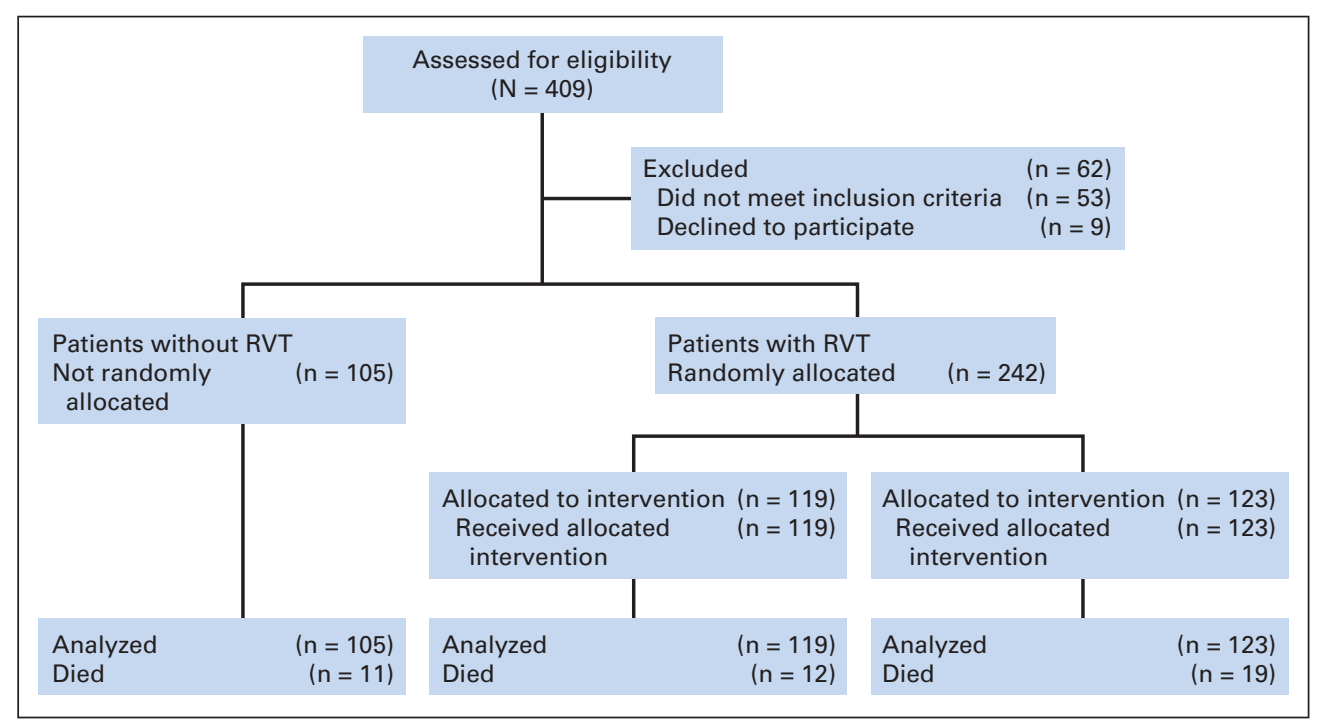

Fig 1. CONSORT diagram. Trial profile. RVT, residual vein thrombosis.

negative D-dimer test may support the safe withdrawal of VKA from 3 to 6 months after DVT. ${ }^{10}$ Conversely, RVT has been associated with an increased risk for recurrent VTE in both idiopathic and provoked DVT. ${ }^{11-13}$ In comparison to the D-dimer, RVT is not influenced by factors acting on blood coagulation. The use of RVT to optimize the duration of LMWH treatment in patients with cancer with acute VTE is still unexplored.

We therefore performed a randomized study in patients with cancer with a first episode of symptomatic lower-limb DVT to test the hypothesis that RVT may be used to determine the optimal duration of LMWH treatment.

\section{PATIENTS AND METHODS}

\section{Study Population}

Inclusion criteria were age $\geq 18$ years; symptomatic proximal DVT detected by compression ultrasonography (C-US); and active cancer, defined as metastatic or locally advanced lung, GI (stomach, colon, or rectum), pancreatic, breast, ovarian, or head and neck cancer or blood cancer treated with LMWH for 6 months after the index event. ${ }^{5}$ Patients with active cancer and a DVT episode occurring after surgery for cancer were also eligible for the study. Exclusion criteria were Eastern Cooperative Oncology Group performance status more than 2; previous VTE; antiphospholipid antibody syndrome, or other known thrombophilic states (eg, deficiency in antithrombin, protein $\mathrm{C}$ and S, homozygosity for factor V Leiden or factor II G20210A mutations or heterozygous combinations thereof); conditions not otherwise specified that required prolonged anticoagulation as for any previous thrombosis; active bleeding or bleeding requiring hospitalization, transfusion, or surgery in the past 4 weeks; intracranial bleeding over the past 6 months; high risk of bleeding (international normalized ratio or activated partial thromboplastin time ratio $>1.3$ or a platelet count $\left.<75 \times 10^{9} / \mathrm{L}\right)^{5}$; active gastric or duodenal ulcer; cerebral metastases; severe and uncontrolled hypertension; creatinine clearance less than $30 \mathrm{~mL} / \mathrm{min}$; severe liver insufficiency; or unavailability for follow-up. Patients did not undergo imaging for PE if they were asymptomatic. Patients who were symptomatic for PE or who had an imaging result positive F1, for PE were excluded (Fig 1).

AQ:F-G The study was carried out in accordance with the provisions of the Declaration of Helsinki and local regulations. Eligible patients were enrolled after written informed consent was provided. The protocol was approved by the institutional review board at each study center.

\section{Study Design and Procedures}

This multicenter prospective study was carried out between October 2005 and April 2010. At enrollment, 6 months from the index DVT, all patients underwent C-US of the affected and contralateral leg. Each enrolling physician had to have experience in C-US or received an appropriate training on C-US. Images were obtained from the transverse section only. Lumen compressibility was then evaluated by gentle pressure of the probe; RVT diameter was taken by measuring the distance between the anterior and posterior walls of the vein on freeze-frame B-mode images during compression with the ultrasound probe. ${ }^{14}$ The examination was performed with the patient in the supine position with the leg externally rotated and slightly flexed at the knee. Measurements were taken at the common femoral vein $1 \mathrm{~cm}$ below the inguinal ligament and at the popliteal vein at the most prominent crease in the midpopliteal fossa. RVT was calculated ${ }^{12}$ according to the following formula: $\mathrm{RVT}=$ vein diameter during compression $($ diameter $\mathrm{B}) \times 100 /$ vein diameter before compression (diameter A). RVT was arbitrarily scored as absent when the value was less than $40 \%$ of vein diameter. The patient was considered to have RVT when a persisting thrombus was present in at least one of the two examined segments (Fig 2) in each leg. The choice of vein segments to examine F2 was based on the evidence that, from proximal to distal veins, the specificity and reproducibility of the method declines with a high risk of false results distally to the popliteal vein.

Patients with RVT were then randomly assigned to either continue LMWH (nadroparine) or stop it (groups A1 and A2, respectively). Nadroparin was administered at $75 \%$ of full dose ( $97 \mathrm{IU}$ anti-activated coagulation factor $\mathrm{X}$ per kilogram twice daily) for 6 additional months on the basis of the results of randomized studies that evaluated LMWH in comparison to VKA, ${ }^{5,15}$ and it was administered at this fixed dose for the entire duration of the study. All patients with no evidence of RVT stopped anticoagulation (group B; Fig 3). F3 After the first C-US performed at the time of enrollment, patients underwent additional testing in addition to scheduled follow-up visits only when recurrence was clinically suspected. Fatal $\mathrm{PE}$ as a cause of death was excluded on the basis of the absence of clinical symptoms or on normal imaging results.

\section{Random Assignment}

Patients with RVT were allocated to either stop or continue LMWH. Random assignment was determined by a sealed-envelope technique based on clinical chart number with a block size of 10 . Patients and treating physicians were not masked to treatment or status of RVT.

\section{Study Outcomes and Follow-Up}

All enrolled patients were observed for 1 year after LMWH discontinuation (Fig 3 ) and were seen at their reference center at intervals of 3 months. 


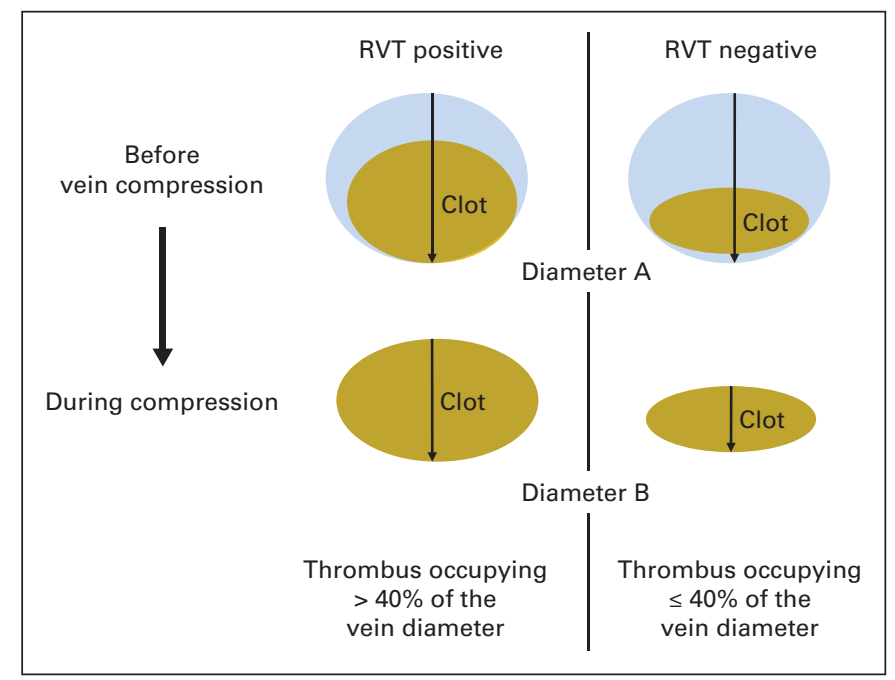

Fig 2. Evaluation of residual vein thrombosis (RVT). RVT was calculated according to the following formula: RVT = vein diameter during compression (diameter B) $\times$ 100/vein diameter before compression (diameter A).

Follow-up visits consisted of clinical examination and laboratory and imaging tests to check for persistent active cancer when needed; C-US was not performed at these contacts. Follow-up visits lasted 18 months in group A1 and 12 months in groups A2 and B. Uniformity of follow-up visits was monitored by regular computer checking in each center.

The primary end point was the time to recurrent VTE, and the secondary end point was major bleeding. The choice of the primary outcome measure derives from the interest in evaluating the opportunity of prolonged treatments of DVT in patients with cancer, assuming that all patients undergo standard 6 months of treatment. Patients were instructed to contact the center if symptoms suggestive of VTE or bleeding developed. The following symptoms were suggestive of RVT: pain, increased volume, or temperature or redness of the leg. In cases of recurrence, C-US was performed, and test results were compared with baseline. Diagnosis of recurrent DVT was made if a previously fully compressible segment became no longer compressible, or if an increase of more than $4 \mathrm{~mm}$ in the diameter of the residual thrombus during compression was detected ${ }^{16}$; in undetermined cases, repetition of the test (after 5 to 7 days) or contrast venography was performed. In patients with possible $\mathrm{PE}$, diagnosis of recurrence was based on objective algorithms with the use of clinical probability, ventilation-perfusion lung scanning, or helical computed tomography. ${ }^{17,18}$ Major bleeding was defined as a decrease in hemoglobin of more than $2.0 \mathrm{~g} / \mathrm{dL}$, intracranial or retroperitoneal bleeding, bleeding requiring surgery or blood transfusion, or any other bleeding necessitating suspension of anticoagulation and hemostatic approaches. ${ }^{9}$ Minor bleeds comprised all other events. All outcomes and deaths were evaluated by a central committee whose members were unaware of the patient's name, enrolling center, results of RVT assays, and group assignment. Committee members also reviewed all the results of clinical investigations.

\section{Statistical Analysis}

The sample size was calculated, taking into account an incidence of $20 \%$ for recurrent thrombotic events for the group with the best prognosis (group B), ${ }^{4}$ and postulating an event rate of $20 \%$ in group A1 and 30\% in group A2. An overall sample size of 300 patients ( 100 for each study group) was calculated (SPSS Sample Power, version 3.0.1; IBM, Chicago, IL) to achieve a power of $80 \%$ to document a difference of at least $15 \%$ in at least one of the different head-to-head comparisons on the basis of the Bonferroni method for distributing type I error (0.05) among multiple comparisons. To monitor the safety of the trial, a safety analysis was planned after enrollment of two thirds of the total patient population. Before study onset, we set up an internal quality control system to assess intra- and interexaminer reproducibility for RVT analysis among operators by using Cohen's unweighted $\kappa$ test. $^{19}$

Baseline differences between groups were assessed by the $\chi^{2}$ test (Yates' correction) for categorical variables, and the univariable analysis of variance AQ: K for parametric analyses. A Kaplan-Meier curve (log-rank test) was used to estimate the cumulative probability of symptomatic recurrent vein thrombosis events. Hazard ratios (HRs) for the treatment effects and their 95\% CIs were calculated by using the Cox proportional hazards models and were adjusted for age, sex, previous surgery, and presence of metastasis. Data were analyzed on an intention-to-treat basis by using Epi Info software, version 6.0 (Centers for Disease Control and Prevention, Atlanta, GA) and SPSS Software, version 14.0 (SPSS, Chicago, IL). All $P$ values were two-tailed; Bonferroni-adjusted $P$ values less than .05 were considered statistically significant.

\section{RESULTS}

\section{Patients and Treatment Groups}

Of the 409 evaluated patients, 62 were excluded: nine did not provide informed consent, 18 required long-term anticoagulation,
Fig 3. Study design. A1 indicates patients with residual vein thrombosis (RVT) who continued low molecular weight heparin (LMWH) for an additional 6 months; A2 indicates patients with RVT randomly assigned to stop LMWH treatment; $B$ indicates patients without RVT who stopped LMWH treatment. C-US, compression ultrasonography; DVT, deep vein thrombosis; $R$, randomization; Time 6, after 6 months; Time 12, after 12 months; Time 18, after 18 months. 


\section{Napolitano et al}

\begin{tabular}{|c|c|c|c|c|c|c|c|}
\hline \multirow[b]{2}{*}{ Characteristic } & \multicolumn{2}{|c|}{$\begin{array}{l}\text { Group A1 } \\
(n=119) \\
\end{array}$} & \multicolumn{2}{|c|}{$\begin{array}{l}\text { Group A2 } \\
(n=123)\end{array}$} & \multicolumn{2}{|c|}{$\begin{array}{l}\text { Group B } \\
(n=105)\end{array}$} & \multirow[b]{2}{*}{$P^{*}$} \\
\hline & No. & $\%$ & No. & $\%$ & No. & $\%$ & \\
\hline Age, years & \multirow{2}{*}{\multicolumn{2}{|c|}{613}} & \multirow{2}{*}{\multicolumn{2}{|c|}{62.1}} & \multirow{2}{*}{\multicolumn{2}{|c|}{61.4}} & $.856 \dagger$ \\
\hline Mean & & & & & & & \\
\hline SD & \multicolumn{2}{|c|}{14.7} & \multicolumn{2}{|c|}{13.7} & \multicolumn{2}{|c|}{13.8} & \\
\hline Male sex & 66 & 55.4 & 68 & 55.3 & 58 & 55.2 & .999 \\
\hline Body mass index, $\mathrm{kg} / \mathrm{m}^{2}$ & \multirow{2}{*}{\multicolumn{2}{|c|}{24.1}} & \multirow{2}{*}{\multicolumn{2}{|c|}{24.2}} & & & $.618+$ \\
\hline Mean & & & & & \multicolumn{2}{|c|}{23.9} & \\
\hline SD & \multicolumn{2}{|c|}{2.9} & \multicolumn{2}{|c|}{3.0} & \multicolumn{2}{|c|}{3.1} & \\
\hline Recent cancer surgerył & 75 & 63.0 & 78 & 63.4 & 65 & 61.9 & .970 \\
\hline Chemotherapy§ & 54 & 45.3 & 57 & 46.3 & 42 & 40.0 & .055 \\
\hline Radiotherapy§ & 24 & 20.1 & 27 & 21.9 & 22 & 20.9 & .943 \\
\hline Hormone therapy§ & 12 & 10.0 & 14 & 11.3 & 11 & 10.4 & .945 \\
\hline Central venous catheter§ & 48 & 40.3 & 48 & 39.0 & 34 & 32.3 & .426 \\
\hline Metastasis & 54 & 21.8 & 55 & 25.2 & 48 & 15.2 & .988 \\
\hline \multicolumn{7}{|l|}{ Index venous thrombosis } & .982 \\
\hline \multicolumn{8}{|l|}{$\begin{array}{l}\text { DVT at one site (popliteal or } \\
\text { common femoral) }\end{array}$} \\
\hline DVT at two sites (popliteal & 66 & 55.5 & 68 & 55.3 & 57 & 54.3 & \\
\hline Left side & 91 & 76.5 & 95 & 77.2 & 80 & 76.2 & .359 \\
\hline \multicolumn{8}{|c|}{$\begin{array}{l}\text { NOTE. Group A1, patients with residual vein thrombosis (RVT) who continued } \\
\text { low-molecular-weight heparin (LMWH) for an additional } 6 \text { months; group A2, } \\
\text { patients with RVT randomly assigned to stop LMWH; group B, patients } \\
\text { without RVT who stopped LMWH. } \\
\text { Abbreviations: DVT, deep vein thrombosis; SD, standard deviation. } \\
{ }^{*} P \text { value refers to } \chi^{2} \text { test unless otherwise specified. } \\
\text { tUnivariable analysis of variance test. } \\
\text { fIn the past } 3 \text { months. } \\
\S \mid n \text { the past } 3 \text { months or ongoing. }\end{array}$} \\
\hline
\end{tabular}

seven had low platelet count, 12 had recent surgery, three had cerebral metastases, and the remaining 13 had organ failure (Fig 1). A total of 347 patients were included in the study. RVT was detected in 242 patients $(69.7 \%)$ who were then randomly assigned to continue (119 patients; group A1) or discontinue (123 patients; group A2) treatment with LMWH. RVT was absent in 105 patients (30.3\%; group B). T1, Baseline patient characteristics are reported in Table 1. Cancer characteristics, site, and chemotherapy treatments in each group are reported in Tables 1 and 2. Twenty-three percent of patients had a hematologic cancer, mostly lymphoma (29 [35.8\%] of 81; Table 2). Considering the prevalence of metastatic cancer, cancer types, and ongoing chemotherapy, there were no statistically significant differences between groups.

\section{Outcomes}

Overall, 18 of the 119 patients in group A1 developed recurrent VTE compared with 27 of 123 patients in group A2. The 12-month cumulative recurrent VTE rates were $15.1 \%$ and $21.9 \%$, respectively. The adjusted HR for group A2 versus A1 was 1.58 (95\% CI, 0.8 to 3.0; $P=.175)$. Three of the 105 patients in group B developed recurrent VTE. The 12-month cumulative rate of recurrence was 2.8\% (Table T3 3). The adjusted HR for group A2 versus group B was 9.56 (95\% CI, AQ:M-N 2.8 to $28.5 ; P<.001)$, although adjusted HR for group A1 versus group B was 6.0 (95\% CI, 1.7 to $21.2 ; P=.005)$.

In total, 30 isolated DVTs of the lower limbs occurred among groups; in 12 patients, thrombosis occurred in the contralateral leg. In detail, four DVTs of the contralateral leg occurred in group A1,

\begin{tabular}{|c|c|c|c|c|c|c|}
\hline \multirow[b]{2}{*}{ Cancer Site } & \multicolumn{2}{|c|}{$\begin{array}{l}\text { Group A1 } \\
(\mathrm{n}=119)\end{array}$} & \multicolumn{2}{|c|}{$\begin{array}{l}\text { Group A2 } \\
(n=123)\end{array}$} & \multicolumn{2}{|c|}{$\begin{array}{l}\text { Group B } \\
(n=105)\end{array}$} \\
\hline & No. & $\%$ & No. & $\%$ & No. & $\%$ \\
\hline Lung & 6 & 5.0 & 6 & 4.9 & 4 & 3.8 \\
\hline GI & 6 & 5.0 & 6 & 4.9 & 5 & 4.8 \\
\hline Colon & 16 & 13.5 & 16 & 13.0 & 15 & 14.3 \\
\hline Rectum & 10 & 8.4 & 10 & 8.1 & 10 & 9.5 \\
\hline Breast & 14 & 11.8 & 14 & 11.4 & 14 & 13.3 \\
\hline Genitourinary & 14 & 11.8 & 14 & 11.4 & 11 & 10.5 \\
\hline Head and neck & 15 & 12.6 & 18 & 14.6 & 13 & 12.4 \\
\hline Blood & 28 & 23.5 & 28 & 22.8 & 25 & 23.8 \\
\hline Hodgkin lymphoma & 7 & 5.9 & 6 & 4.9 & 5 & 4.7 \\
\hline Non-Hodgkin lymphoma & 4 & 3.3 & 4 & 3.2 & 3 & 2.9 \\
\hline Chronic lymphatic leukemia & 12 & 10.1 & 12 & 9.8 & 11 & 10.5 \\
\hline Multiple myeloma & 5 & 4.2 & 6 & 4.9 & 6 & 5.7 \\
\hline Other & 10 & 8.4 & 11 & 8.9 & 8 & 7.6 \\
\hline \multicolumn{7}{|c|}{$\begin{array}{l}\text { NOTE. Group A1, patients with residual vein thrombosis (RVT) who continued } \\
\text { low-molecular-weight heparin (LMWH) for an additional } 6 \text { months; group A2, } \\
\text { patients with RVT randomly assigned to stop LMWH; group B, patients } \\
\text { without RVT who stopped LMWH. }\end{array}$} \\
\hline
\end{tabular}

seven in group A2, and only one in group B. None of the contralateral DVTs occurred in patients with recurrent DVT and PE.

Bleeding events are reported in Table 3 . Three major bleedings occurred in group A1, and two events each occurred in groups A2 and $\mathrm{B}(P=.880)$. Considering the 6- and 12-month follow-up periods separately, at 6 months, four VTE were reported and two major bleeding episodes occurred in group A1; 18 VTE were reported and three bleeding episodes occurred in group A2. At 12 months after random assignment, 10 VTE and two bleeding episodes were recorded in group A1, whereas group A2 had nine VTE and one bleeding episode. After the first 6 months, there were 111 patients still on follow-up in group A1 and 101 in group A2. At 12

Table 3. Recurrent Thromboembolic and Bleeding Events by Treatment Group and Cancer Site

\begin{tabular}{|c|c|c|c|c|c|c|c|}
\hline \multirow[b]{2}{*}{ Event } & \multicolumn{2}{|c|}{$\begin{array}{l}\text { Group A1 } \\
(n=119)\end{array}$} & \multicolumn{2}{|c|}{$\begin{array}{l}\text { Group A2 } \\
(n=123)\end{array}$} & \multicolumn{2}{|c|}{$\begin{array}{l}\text { Group B } \\
(n=105)\end{array}$} & \multirow[b]{2}{*}{$P^{*}$} \\
\hline & No. & $\%$ & No. & $\%$ & No. & $\%$ & \\
\hline Overall events & $18 / 119$ & 15.1 & $27 / 123$ & 21.9 & $3 / 105$ & 2.8 & .0015 \\
\hline Isolated DVT & $9 / 18$ & 50 & $19 / 27$ & 70.4 & $2 / 3$ & 66.7 & .379 \\
\hline DVT and PE & $7 / 18$ & 38.9 & $7 / 27$ & 25.9 & 0 & & .333 \\
\hline PE only & $2 / 18$ & 11.1 & $1 / 27$ & 3.7 & $1 / 3$ & 33.3 & .183 \\
\hline $\begin{array}{c}\text { DVT in not previously } \\
\text { affected leg }\end{array}$ & $4 / 18$ & 22.2 & $7 / 27$ & 25.9 & $1 / 3$ & 33.3 & .906 \\
\hline Major bleeding & 3 & 2.5 & 2 & 1.6 & 2 & 1.9 & .880 \\
\hline Minor bleeding & 7 & 5.9 & 8 & 6.5 & 5 & 4.8 & .851 \\
\hline $\begin{array}{l}\text { Death (as a result of } \\
\text { cancer } \\
\text { progression) }\end{array}$ & 12 & 10.1 & 19 & 15.4 & 11 & 10.5 & .366 \\
\hline
\end{tabular}

NOTE. Group A1, patients with residual vein thrombosis (RVT) who continued low-molecular-weight heparin (LMWH) for an additional 6 months; group A2, patients with RVT randomly assigned to stop LMWH; group $B$, patients without RVT who stopped LMWH. No. columns indicate No. of overall events per total patient group.

Abbreviations: DVT, deep vein thrombosis; PE, pulmonary embolism.

*Bonferroni-adjusted $P$ values refer to $\chi^{2}$ test. 
months, there were 97 patients in group A1 and 82 in group A2 (Fig 3 ). Among patients in group A1, compliance was high: 15 of the 119 patients interrupted LMWH for less than 5 days during study treatment.

Overall, 42 patients (12.1\%) died during 12 months of follow-up, all for progression of cancer: 12 patients (10.1\%) died in group A1, 19 (15.4\%) in group A2, and $11(10.5 \%)$ in group B. No statistically significant difference was found between groups $(P=.366)$. Fatal PE was not reported.

\section{DISCUSSION}

LMWH is currently the standard of care for cancer-related DVT, and guidelines recommend continuation of treatment as long as the neoplasm is active. ${ }^{6}$ However, cancer populations differ substantially in terms of type, stage, histology and, consequently, treatment choice ${ }^{20}$; thus, the duration of LMWH treatment for an individual patient is unclear. The optimal duration of anticoagulant therapy should be based on tailoring treatment according to the risk of recurrent VTE. An individual-based approach of tailoring anticoagulant duration based on RVT and D-dimer has been investigated in noncancer populations, ${ }^{10-13}$ but data are lacking in the cancer population. We chose to study RVT rather than D-dimer because the latter is insensitive to factors affecting blood coagulation (such as infections or cancer) and can be determined without interrupting anticoagulation. ${ }^{11-13}$

In our study, all patients underwent RVT assessment after 6 months of LMWH. In those with residual RVT who stopped LMWH (group A2), the incidence of subsequent recurrent VTE was 21.7\% compared with $2.8 \%$ in patients without RVT who stopped treatment (B), an almost eight-fold increased risk. Thus the 6-month RVT is prognostic for recurrent VTE and defines a group of patients at low risk of recurrence. This has obvious implications for clinical practice: in low-risk patients, short-term anticoagulation reduces the clinical burden for both the patient and health care system and substantially reduces the overall risk of bleeding. In the group of patients with RVT at 6 months, the continuation of LMWH did not reduce the incidence of recurrent VTE. Although there was a trend in favor of LMWH, it was not significant, likely because of the small sample size.

Bleeding was low in all groups in our trial, likely because the study population had already been on 6 months of anticoagulant therapy before random assignment; those patients with a bleeding tendency had already self-selected and were excluded. No differences in mortality rates were detected between groups. The trial was underpowered to detect mortality differences. The mortality rates were considerably lower than rates in other trials of LMWH, likely because patients in our trial had to live for 6 months to be eligible. ${ }^{21,22}$

As in the noncancer population, more than $20 \%$ of the recurrent thrombotic events occurred in the contralateral leg, suggesting that RVT is also a marker of an underlying prothrombotic state, thus triggering a sustained hypercoagulability. ${ }^{23}$

This study has several limitations; first, the trial was not blinded to patients and treating physicians. However, committee members, who were unaware of results and treatments, assessed recurrent events, thus reducing the risk of diagnostic suspicion bias. Moreover, the rates of events in our patients are in the range of those reported in the literature. ${ }^{4,23}$ Second, some concerns may arise about the reproducibility of RVT detection. Before the three Duration of Anticoagulation based on Compression Ultrasonography (DACUS) studies AQ: $\mathrm{P}$ (Residual Vein Thrombosis Establishes the Optimal Duration of Oral Anticoagulants [DACUS]; Residual Vein Thrombosis and the Optimal Duration of Low Molecular Weight Heparin in Cancer Patients With Deep Vein Thrombosis [Cancer-DACUS]; and Absence of Residual Vein Thrombosis Permits to Withdrawn Oral Anticoagulants [Exten-DACUS]), we tested RVT assessment on a consecutive series of 64 noncompressible venous segments (popliteal and common femoral veins), and results from intra- and interobserver variation assessment among operators were shown to be adequate $(\kappa, 0.7403 ; 95 \% \mathrm{CI}$, 0.70 to 0.86$).{ }^{11,24}$ In clinical management of DVT, the accuracy and reproducibility of C-US should be improved with training courses. Third, RVT assessment was performed only at study entry. We cannot, however, exclude that during follow-up, some patients, originally without RVT, could have had abnormal results on repeated testing, providing a detectable warning sign of recurrent hypercoagulability and an increased risk of thrombosis. Repeated RVT in patients with an original absence of residual thrombus may be useful in detecting a late relapse even if the patient is asymptomatic, but this hypothesis should be assessed in future studies. Furthermore, exclusion of concomitant PE was based on clinical symptoms, and routine imaging tests at enrollment were not planned, which could have interfered with the management of asymptomatic PE. Fourth, the sample size was quite small. Fifth, in patients without RVT, the incidence of recurrent VTE was lower (3\%) than previously reported. However, if we consider all the patients enrolled (both with and without RVT), the rate of recurrent VTE was as high as 14\%, which is similar to that reported. ${ }^{4-7}$ Another potential limitation is the 6-month difference in follow-up duration between groups A1 and A2, which may have resulted in an underestimate of the event rate in the latter group.

Our results indicate that, after 6 months of standard treatment with LMWH for DVT, the absence of RVT identifies patients with cancer at a low risk for recurrent thrombotic events. This possibility is important in driving a management strategy for both prevention of recurrences and selection of patients who may benefit from a short period of anticoagulation.

\section{AUTHORS' DISCLOSURES OF POTENTIAL CONFLICTS OF INTEREST} $A Q: Q$

The author(s) indicated no potential conflicts of interest.

\section{AUTHOR CONTRIBUTIONS} $\mathrm{AQ}: \mathbf{R}$

Conception and design: Giorgia Saccullo, Alessandra Malato, Delia Sprini, Sergio Siragusa

Collection and assembly of data: Walter Ageno, Davide Imberti, Doris Mascheroni, Eugenio Bucherini, Pina Gallucci, Andrea d'Alessio, Tullia Prantera, Pietro Spadaro, Stefano Rotondo, Pierpaolo Di Micco, Vincenzo Oriana, Oreste Urbano, Francesco Recchia, Angelo Ghirarduzzi, Salvatrice Mancuso

Data analysis and interpretation: Mariasanta Napolitano, Lucio Lo Coco, Alessandra Casuccio, Giovam Battista Rini, Sergio Siragusa Manuscript writing: All authors

Final approval of manuscript: All authors 


\section{REFERENCES}

1. Chew HK, Wun T, Harvey D, et al: Incidence of venous thromboembolism and its effect on survival among patients with common cancers. Arch Intern Med 166:458-464, 2006

2. Sørensen HT, Mellemkjaer L, Olsen JH, et al: Prognosis of cancers associated with venous thromboembolism. N Engl J Med 343:1846-1850, 2000

3. Bick RL: Cancer-associated thrombosis. N Engl J Med 349:109-111, 2003

4. Prandoni $P$, Lensing AW, Piccioli $A$, et al: Recurrent venous thromboembolism and bleeding complications during anticoagulant treatment in $\mathrm{pa}$ tients with cancer and venous thrombosis. Blood 100:3484-3488, 2002

5. Lee AY, Levine MN, Baker RI, et al: Low molecular weight heparin versus a coumarin for the prevention of recurrent venous thromboembolism in patients with cancer. N Engl J Med 349:146-153, 2003

6. Kearon C, Akl EA, Comerota AJ, et al: Antithrombotic therapy for VTE disease: Antithrombotic Therapy and Prevention of Thrombosis, 9th edAmerican College of Chest Physicians EvidenceBased Clinical Practice Guidelines. Chest 141: e419S-e494S, 2012

7. Hull RD, Pineo GF, Brant RF, et al: Long-term low-molecular-weight heparin versus usual care in proximal-vein thrombosis patients with cancer. Am J Med 119:1062-1072, 2006

8. Agnelli G, Prandoni P, Santamaria MG, et al: Three months versus one year of oral anticoagulant therapy for idiopathic deep venous thrombosis: Warfarin Optimal Duration Italian Trial Investigators. N Engl J Med 345:165-169, 2001

9. Palareti G, Leali N, Coccheri S, et al: Bleeding complications of oral anticoagulant treatment: An inception-cohort, prospective collaborative study (ISCOAT) - Italian Study on Complications of Oral Anticoagulant Therapy. Lancet 348:423-428, 1996

10. Palareti G, Cosmi B, Legnani C, et al: D-dimer testing to determine the duration of anticoagulation therapy. N Engl J Med 355:1780-1789, 2006

11. Prandoni $P$, Lensing $A W$, Prins $M H$, et al: Residual venous thrombosis as a predictive factor of recurrent venous thromboembolism. Ann Intern Med 137:955-960, 2002

12. Siragusa $S$, Malato $A$, Anastasio $R$, et al: Residual vein thrombosis to establish duration of anticoagulation after a first episode of deep vein thrombosis: The Duration of Anticoagulation based on Compression UltraSonography (DACUS) study. Blood 112:511-515, 2008

13. Siragusa S, Malato A, Saccullo G, et al: Residual vein thrombosis for assessing duration of anticoagulation after unprovoked deep vein thrombosis of the lower limbs: The extended DACUS study. Am J Hematol 86:914-917, 2011

14. Bates $S M$, Jaeschke $R$, Stevens $S M$, et al: Diagnosis of DVT: Antithrombotic Therapy and Prevention of Thrombosis, 9th ed-American College of Chest Physicians Evidence-Based Clinical Practice Guidelines. Chest 141:e351S-e418S, 2012

15. Meyer G, Marjanovic Z, Valcke J, et al: Comparison of low-molecular-weight heparin and warfarin for the secondary prevention of venous thromboembolism in patients with cancer: A randomized controlled study. Arch Intern Med 162:1729-1735, 2002

16. Prandoni P, Lensing AW, Bernardi E, et al: The diagnostic value of compression ultrasonography in patients with suspected recurrent deep vein thrombosis. Thromb Haemost 88:402-406, 2002

17. Fedullo PF, Tapson VF: Clinical practice: The evaluation of suspected pulmonary embolism. N Engl J Med 349:1247-1256, 2003

18. Kearon C: Diagnosis of pulmonary embolism. CMAJ 168:183-194, 2003

19. Brennan $P$, Silman A: Statistical methods for assessing observer variability in clinical measures. BMJ 304:1491-1494, 1992

20. Imberti D, Agnelli G, Ageno W, et al: Clinical characteristics and management of cancer-associated acute venous thromboembolism: Findings from the MASTER Registry. Haematologica 93:273-278, 2008

21. Klerk CP, Smorenburg SM, Otten HM, et al: The effect of low molecular weight heparin on survival in patients with advanced malignancy. J Clin Oncol 23:2130-2135, 2005

22. Kakkar AK, Levine MN, Kadziola Z, et al: Low molecular weight heparin, therapy with dalteparin, and survival in advanced cancer: The fragmin advanced malignancy outcome study (FAMOUS). J Clin Oncol 22:1944-1948, 2004

23. Noble S, Pasi J: Epidemiology and pathophysiology of cancer-associated thrombosis. $\mathrm{Br} \mathrm{J}$ Cancer 102:S2-S9, 2010

24. Tan $\mathrm{M}$, Bornais $\mathrm{C}$, Rodger $\mathrm{M}$ : Interobserver reliability of compression ultrasound for residual thrombus after first unprovoked deep vein thrombosis. J Thromb Haemost 10:1775-1782, 2012

\section{Affiliations}

Mariasanta Napolitano, Giorgia Saccullo, Alessandra Malato, Delia Sprini, Lucio Lo Coco, Salvatrice Mancuso, Alessandra Casuccio, Giovam Battista Rini, and Sergio Siragusa, Università degli Studi di Palermo, Palermo; Walter Ageno, Università dell'Insubria, Varese; Davide Imberti, Ospedale di Piacenza, Piacenza; Doris Mascheroni, Istituto Clinico Villa Aprica, Como; Eugenio Bucherini, Ospedale di Faenza, Faenza AQ: S Ravenna; Pina Gallucci, Centro Regionale Oncologico Basilicata, Rionero in Volture; Andrea D’Alessio, Policlinico San Marco, Zingonia; Tullia Prantera, Ospedale S. Giovanni di Dio, Crotone; Pietro Spadaro, Villa Salus, Messina; Stefano Rotondo, Centro Studi Neurolesi; Oreste Urbano, Ospedale Piemonte, Messina; Pierpaolo Di Micco, Ospedale Fatebenefratelli, Napoli; Vincenzo Oriana, Azienda Ospedaliera di Reggio Calabria, Reggio Calabria; Francesco Recchia, Ospedale di Avezzano, Avezzano; and Angelo Ghirarduzzi, Azienda Ospedaliera di Reggio Emilia ArcispedAQ:T-U ale S. Maria Nuova, Reggio Emilia, Italy. 